explored the remoter shores and volcanoes, she took up photography to give expression to her love of the islands and her search for beauty. She ends her story by explaining that she must now leave the Galapagos because the quiet hamlet where she lived has suddenly boomed into a sprawling tourist village, dominated by the profit motive. Her feelings are understandable, although she might agree that the commercialization of this little human settlement is a small price to pay for the preservation of nine-tenths of the archipelago as a national park, free from residents, buildings, private property or development and with strict protection for wildlife and wildnerness.

Mrs Moore's book stands or falls by its copious illustrations. They are different from the ordinary run of Galapagos photographs and may disappoint some visitors because she does not see her islands through a tourist's eyes: but then, the same could be said of Turner's greatest pictures. Moreover, few visitors are on the rim of the volcano before dawn to observe and record the fascinating play of light and shadow. It is a matter of taste, but personally I find several of the reproductions too dark, and I would gladly have sacrificed some of the 300 colour photographs in return for a less cramped lay-out of the rest. But by any standards the book is full of unusual and outstanding pictures of the land, the sea and the peculiar animals and plants of the wild Galapagos.

G.T. CORLEY SMITH

\title{
Ecology of Desert Organisms, by G.N. Louw and M.K. Seely. Longman, f8.50.
}

Deserts can have an irresistible lure. They may be too hot or too cold for comfort but deserts of both extremes offer a refuge from civilization, where solitude, clarity of air, beauty of scenery and simple, if arduous, living can be found. For the biologist, deserts have much to offer because of their harshness and simplicity. Extremes of environment have necessitated the evolution of striking adaptations in morphology, physiology and behaviour to deal with the limiting factors of heat, water and food. Not too many organisms have overcome these problems, so the ecology of deserts is relatively simple: there are few species eating one another.

The authors consider hot deserts only and, drawing on their own researches, they concentrate on the Namib desert - that home of fascinating animals which has become familiar through a deservedly much repeated television film. The reader who has seen the film is reminded of the beetle that drinks by collecting foggy dewdrops on its nose and the dune gecko which lifts its feet to avoid the burning sand, while new snippets include the ground squirrel that uses its bushy tail as a parasol and the gerbil that tunnels where gemsbok urine has stabilized the sand.

The ingenuity of desert organisms seems inexhaustible, although the finding of common solutions in different deserts is also well marked, as in the parallelism of the 'sidewinding' gait of Namib adder and American rattler. The authors have used these gems of desert natural history to illustrate discussions on the survival of species and the more intricate problems of communities, such as energy flow and production, competition and niches, diversity and succession. The result is a book for broadening one's knowledge of ecology in general and a very useful summary of desert ecology in particular.

As to conservation, the final chapter on Man and the Desert shows how native inhabitants are as much a part of the ecosystem as other species, but that the system is fragile and easily destroyed by the mounting pressures of rising population and advancing technology coming from outside. 